\title{
Sugar-Induced Tolerance to the Salt Stress in Maize Seedlings by Balancing Redox Homeostasis
}

\author{
Zhao Ying $^{1}$, Xu Jing-yu ${ }^{1,2}$, He Lin ${ }^{1,2}$, Yang Ke-jun ${ }^{1,2}$, Zhao Chang-jiang ${ }^{1,2}$, Wang Zhi-hui ${ }^{1,2}$, \\ Li Zuo-tong 1,2 , * \\ ${ }^{1}$ Department of Agronomy, College of Agronomy Heilongjiang Bayi Agricultural University, Daqing, China \\ ${ }^{2}$ Department of Agronomy, Key Laboratory of Crop Germplasm Improvement and Cultivation in Cold Regions of Heilongjiang Province \\ Education Department, Daqing, China
}

\section{Email address:}

Tianshi198937@126.com (Zhao Ying),1xg6401999@163.com (Li Zuo-tong)

*Corresponding author

\section{To cite this article:}

Zhao Ying, Xu Jing-yu, He Lin, Yang Ke-jun, Zhao Chang-jiang, Wang Zhi-hui, Li Zuo-tong. Sugar-Induced Tolerance to the Salt Stress in Maize Seedlings by Balancing Redox Homeostasis. Agriculture, Forestry and Fisheries. Vol. 5, No. 4, 2016, pp. 126-134. doi: $10.11648 /$ j.aff. 20160504.15

Received: March 23, 2016; Accepted: July 21, 2016; Published: August 8, 2016

\begin{abstract}
Effects of exogenous glucose (Glc) and sucrose (Suc) on salt resistance, (glucose-6-phosphate dehydrogenase) G6PDH activity, ASA-GSH cycle and reactive oxygen species metabolism in maize leaves were studied. Seedings at two leaf stage were pretreated by $1 / 2$ Hoagland nutrient solution with $0.5 \mathrm{mmol} \cdot \mathrm{L}^{-1} \mathrm{Glc}$, Suc and mannitol for 3 days, some seedlings were left in normal nutrient solution and isotonic maninitol as control and permeability control respectively. Then the plants were cultured by $1 / 2$ Hoagland solution at the concentration of $150 \mathrm{mmol} \cdot \mathrm{L}^{-1} \mathrm{NaCl}$ for 4 days or 6 days. The results showed that pretreatment with $0.5 \mathrm{mmol} \cdot \mathrm{L}^{-1}$ glucose and sucrose for 3 days significantly decreased the thiobarbituric acid reactive substances (TBARS), $\mathrm{H}_{2} \mathrm{O}_{2}$ contents and increased ASA, GSH contents, ASA/DHA, GSH/GSSG ratio and G6PDH activity in leaves of maize seedings under salt stress. We also found that sucrose pretreatment induced the increase of $\mathrm{Ca}^{2+}$-ATPase and maintained the balance of $\mathrm{Ca}^{2+}$ contents under salt stress. In addition, compared with $\mathrm{S}$ treatment, isotonic mannitol pretreatment did not induce any changes of the physiological and biochemical indicators that meant it could not cause improvement of biological indicators of maize seedings. These results indicate that exogenous glucose and sucrose improved ASA-GSH cycle efficiency by participating in the pentose phosphate pathway (OPP), therefore enhanced antioxidant capacity and reduced the damage of active oxygen free radical, and the G6PDH activity induced by glucose and sucrose might serve as signal molecules and be involved in salt resistance of maize seedings.
\end{abstract}

Keywords: Maize (Zea mays L.), Glucose, Sucrose, Salt Stress, Glucose-6-Phosphate Dehydrogenase, Pentose Phosphate Pathway

\section{Introduction}

Salinity is a worldwide resource and ecological problem. Among the $2.7 \times 107 \mathrm{hm}^{2}$ saline area, there are $7 \times 106 \mathrm{hm}^{2}$ farmlands which account for tenth of the total arable land [1]. Due to the improper irrigation and massive usage of chemical fertilizer, the secondary salinization soil area are continue to expend and resulting the yearly decrease of arable land area. According to research, in the next 25 years the arable land will reduce $30 \%$ [2]. Salinity has become the major environmental factor that has a crucial impact of the productivity and quality improvement on maize. As such, it is of the utmost importance to understand how to improved salt tolerance and increase crop productivity under salt stress, in order to solve salinization and ensure food security.

Sugar plays an important role during the life cycle of plants. It is not only the energy source and structure materials, but also acts as signal molecular involved in biotic and abiotic stresses response during the entire process 
of growth and development of plants [3-6]. Recent study shows that sugar has important regulation influence on the production and clearness of ROS and the expression of ROS-response genes [7, 8]. First of all, sugar participates in the metabolic pathways of ROS production. In animal cells, the high concentration of glucose (Glc) could induce the generation of ROS by activate the NADPH oxidase in cytoplasm membrane. Among advanced plant cells, the excessiveness of soluble sugar might suppresses the expression of photosynthetic gene. For example, sugar can participate in the regulation of the genes which involved with Calvin cycle, which might lead to the inadequate supplement of $\mathrm{NADP}^{+}$and causing the occurrence of electronic leakage in PSI and superoxide anion $\left(\mathrm{O}_{2}^{-}\right)$ formation. Secondly, sugar also involves in some metabolic pathways of ROS clearness. Take the pentose phosphate pathway (OPP) as an example, during which the glucose-6-phosphate dehydrogenase (G6PDH) act as the speed limit enzymes in OPP pathway and control the carbon flow as well as the generation of NADPH of this pathway [9, 10]. Under dark condition, the exogenous Glc in potatoes could significantly improve the activity of G6PDH in cytoplasm and positively regulate the production of $\mathrm{NADPH}$, which is of great significance to the maintenance of balance of oxidation reduction reaction inside cells [11].

In salt stress environment, exogenous Suc in rice could raise the content of glucose and fructose, which lead to the improvement of salt tolerance in rice [12]. The study conduct by Boriboonkase [13] found that under high concentrate salt treatment $\left(342 \mathrm{mmol} \cdot \mathrm{L}^{-1} \mathrm{NaCl}\right)$, rice seeds processed with Suc showed a higher resistance to salt. By analysis the transcript level of Arabidopsis thaliana genes, it is found that Glc could induce the expression of a large number of stress-response genes [14]. In addition, the expression of glucose metabolism enzyme gene in Arabidopsis thaliana significantly improved under abiotic stress, which shows that sugar signal plays an important role in plants response to adversity [15].

To date, the studies on sugar signal and plants resistance are mainly focus on $\mathrm{C} 3$ plants, and the studies on $\mathrm{C} 4$ plants are very rare. Although it is known that the pretreatment with sugar could reduce the inhibition of salt stress on maize growth, but the reports are very rare on whether this attenuation is associated with redox or calcium signals. This study mainly focus on the physiological traits of maize under salt stress, and by using pretreatment with Glc and Suc it discussed the influences on redox equilibrium, active oxygen metabolism and $\mathrm{Ca}^{2+}$ content in corn leaf under salt stress.

\section{Materials and Methods}

\subsection{Plant Materials}

Kenyu No.6 seeds were used as the plant material in this experiment and were obtained from Maize Breeding Research Center of Heilongjiang Bayi Agricultural University in Daqing city $\left(45^{\circ} 46^{\prime} \mathrm{N}, 124^{\circ} 19^{\prime} \mathrm{E}\right)$,
Heilongjiang Province. China.

\subsection{Seedling Growth}

This study was conducted in key laboratory of crop improvement and cultivation of Heilongjiang Bayi Agricultural University from 2013 to 2015 . Healthy seeds of similar size, color and mass were selected. Seeds were surface sterilized with $10 \% \mathrm{NaClO}$ for $20 \mathrm{~min}$ to avoid fungus attack, and subsequently washed with deionised water. Seeds with same length of buds were placed in growth chamber and soaked with $1 / 2$ Hoagland nutrient solution until three-leaf-stage under a 12-h light $25 \pm 2{ }^{\circ} \mathrm{C} / 12$-h dark $20 \pm 2^{\circ} \mathrm{C}$ regime, with $25-37.5$ $\mu \mathrm{mol} \mathrm{m} \mathrm{m}^{-2}$ light intensity and $60 \%-80 \%$ relative humidity. After seedlings mentioned above were treated with 0.5 $\mathrm{mmol} \cdot \mathrm{L}^{-1}$ Glc, Suc, 1/2 Hoagland nutrient solution with mannitol (osmosis comparison) and 1/2 Hoagland nutrient solution for $3 \mathrm{~d}$, they were treated with $150 \mathrm{mmol} \cdot \mathrm{L}^{-1} \mathrm{NaCl}$ (prepared with 1/2 Hoagland nutrient solution) in order to conduct salt stress treatment. For non-salt stress comparisons, maize was treated with corresponding sugar or blank. There were seven treatments used in this study, namely control (CK), salt treatment $(\mathrm{S})$, Glc pretreatment $(\mathrm{G})$, Suc pretreatment $(\mathrm{T})$, salt treatment after Glc pretreatment $(\mathrm{G}+\mathrm{S})$, salt treatment after Suc pretreatment $(\mathrm{T}+\mathrm{S})$ and salt treatment after mannitol pretreatment $(\mathrm{M}+\mathrm{S}) .100$ seeds were evaluated in each test and all tests were repeated three times. After salt treatment for $4 \mathrm{~d}$, the second fully expanded leaves were used in the determination of physiological indexes. The growth indicators were determined on $6 \mathrm{~d}$ treatment samples.

\subsection{Growth Performance}

After 4 days of germination, length measurements of coleoptile and radicle were measured from 30 plants per replicate. Those samples were dried in a hot-air oven at $105^{\circ} \mathrm{C}$ for $15 \mathrm{~min}$, and then at $80^{\circ} \mathrm{C}$ for $48 \mathrm{~h}$ and incubated in a desiccators for dry weight measurement. The relative growth rate was determined according to the formula of Kingsbury et al. [16]:

$$
R G R=\frac{\operatorname{Ln} W_{2}-\operatorname{Ln} W_{1}}{t_{2}-t_{1}}
$$

Where $W_{1}$ and $W_{2}$ are dry weights obtained from the first and second harvests, respectively, and $t_{2}-t_{1}$ is the time interval in days between those harvests. The RGR represents that growth obtained relative to the amount of tissue present, expressed as a daily average. This is a reflection of growth potential under the conditions imposed.

To analyze the data, RGR values obtained for plants grown in the salt treatment were transformed into percentages of control values for each harvest. A one-tailedt test between paired variates was then performed.

\subsection{Biochemical Measurements}

\subsubsection{Measurement of Lipid Peroxidation and $\mathrm{H}_{2} \mathrm{O}_{2}$}

The level of lipid per oxidation in Maize seedling 
samples was estimated by thiobarbituric acid-reactive substances (TBARS). The contents of TBARS determined according to the method of Hodges [17]. Embryo samples $(0.5 \mathrm{~g})$ were homogenized in $5 \mathrm{~mL}$ of $5 \%(\mathrm{w} / \mathrm{v})$ trichloroacetic acid (TCA). To $2 \mathrm{~mL}$ supernatant, $2 \mathrm{~mL}$ of $0.67 \%(\mathrm{w} / \mathrm{v})$ thiobarbituric acid containing $15 \%(\mathrm{w} / \mathrm{v}) \mathrm{TCA}$ was added. The absorbance of the supernatant was recorded at 450, 532 and $600 \mathrm{~nm}$ and TBARS content was expressed as $1 \mathrm{nmol} \mathrm{TBARS} \mathrm{g}^{-1} \mathrm{FW}$.

The measurement of $\mathrm{H}_{2} \mathrm{O}_{2}$ was following the method of Velikova [18]. $0.5 \mathrm{~g}$ dry sample was put into $5 \mathrm{ml} 0.1 \%$ TCA for ice bath grinding, and then centrifuged it in $4{ }^{\circ} \mathrm{C}$ $12000 \mathrm{~g}$ for $15 \mathrm{~min}$. Put $1-2 \mathrm{ml}$ supernatant into $0.5 \mathrm{ml} 10$ $\mathrm{mmol} \cdot \mathrm{L}^{-1}$ potassium phosphate buffer $(\mathrm{pH} \mathrm{7.0)}$ and $1 \mathrm{ml} 1$ $\mathrm{mol} \cdot \mathrm{L}^{-1} \mathrm{KI}$ to colorimetric in $390 \mathrm{~nm} .0 .1 \%$ TCA was used as control.

\subsubsection{Measurement of Ascorbic acid and Glutathione}

The measurement of ASA was following the method of Fryerd et al. [19], and GSH was following Nagalakshmi and

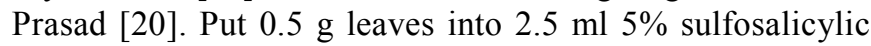
acid for grinding, and then centrifuged it in $4{ }^{\circ} \mathrm{C} 20000 \mathrm{~g}$ for $20 \mathrm{~min}$. The supernatant can be used in the measurement of ASA, GSH, DHA, and GSSG.

\subsubsection{Measurement of G6PDH Dynamic}

The measurement of G6PDH dynamic was according to the method of Brouquisse [21]. Put $0.5 \mathrm{~g}$ leaves into $5 \mathrm{ml}$ precooling enzyme extract $\left(0.02 \mathrm{~mol} \cdot \mathrm{L}^{-1}\right.$ Tris- $\mathrm{HCl}, \mathrm{pH} 7.5$, $0.42 \mathrm{~mol} \cdot \mathrm{L}^{-1}$ mannitol, $5 \mathrm{mmol} \cdot \mathrm{L}^{-1} \mathrm{KCl}, 5 \mathrm{mmol} \cdot \mathrm{L}^{-1}$ $\mathrm{MgSO}_{4}$ ) for ice bath grinding into homogenate. Four layer gauze is used to filter the homogenate and centrifuge the filtrate under $0^{\circ} \mathrm{C} 3000 \mathrm{r}$ for $10 \mathrm{~min}$. Put $100 \mu \mathrm{l}$ supernatant into $2 \mathrm{ml}$ reaction buffer $\left(0.5 \mathrm{mmol} \cdot \mathrm{L}^{-1} \mathrm{NADP}\right.$, $5 \mathrm{mmol} \cdot \mathrm{L}^{-1}$ glucose-6-phosphate, $5 \mathrm{mmol} \cdot \mathrm{L}^{-1} \mathrm{MgCl}_{2}, 0.05$ $\mathrm{mmol} \cdot \mathrm{L}^{-1}$ Tris- $\mathrm{HCl}, \mathrm{pH} 8.2$ ) to colorimetric in $340 \mathrm{~nm}$. After $5 \mathrm{~min}$, the changes of OD were measured. The relative enzyme dynamic of G6PDH was represented by the changes of the optical density of per mg enzyme protein. The measurement of enzyme protein was following the method of Braford [22].

\subsubsection{The Determination of $\mathrm{Ca}^{2+}$-ATPase Activity}

The preparation of Chloroplast was followed Liu et al. [23]. After the remove the midrib form the leaves, $0.5 \mathrm{~g}$ leaves were weighed and added with $10 \mathrm{ml}$ precooling chloroplast preparation liquid (including $0.05 \mathrm{~mol} \cdot \mathrm{L}^{-1}$ potassium phosphate buffer, $\mathrm{pH} 7.2,0.3 \mathrm{~mol} \cdot \mathrm{L}^{-1}$ sucrose solution, $0.1 \mathrm{~mol} \cdot \mathrm{L}^{-1} \mathrm{KCl}$ solution ). Then grinding it for 1 min under ice bath and filter the homogenate using 4-layer gauze. The filtrate was centrifuged for 10 min under $0^{\circ} \mathrm{C}$ and the supernatant was removed. The subsidence was suspended with $10 \mathrm{ml}$ preparation liquid before centrifuged for $10 \mathrm{~min}$ under $3000 \mathrm{r}$. Take $5 \mathrm{ml}$ subsidence and suspended it with $5 \mathrm{ml}$ preparation liquid, namely the chloroplast suspension.

Following the method of Huang et al. [24], take $1 \mathrm{ml}$ chloroplast suspension and added $1 \mathrm{ml}$ activation solution (including $0.05 \mathrm{~mol} \cdot \mathrm{L}^{-1}$ Tris- $\mathrm{HCl}, \mathrm{pH} \quad 8.0,4 \mathrm{mmol} \cdot \mathrm{L}^{-1}$ EDTA $2 \mathrm{Na}, 2 \mathrm{mmol} \cdot \mathrm{L}^{-1} \mathrm{ATP}$, and $0.4 \mathrm{mg} \cdot \mathrm{mL}^{-1}$ ) into it. After activation for $10 \mathrm{~min}$ under $20^{\circ} \mathrm{C}, 0.1 \mathrm{ml}\left(10 \mathrm{mg} \cdot \mathrm{mL}^{-1}\right)$ bovine serum albumin was added in order to terminate the activation. Take $0.5 \mathrm{ml}$ activated chloroplast suspension immediately and added $1 \mathrm{ml}$ reaction solution (including Tris- $\mathrm{HCl} 100 \mathrm{mmol} \cdot \mathrm{L}^{-1}, \mathrm{pH} 8.0$, ATP $10 \mathrm{mmol} \cdot \mathrm{L}^{-1}, \mathrm{CaCl}_{2}$ $10 \mathrm{mmol} \cdot \mathrm{L}^{-1}$ ) into it. Removed the subsidence after centrifugation, $0.1 \mathrm{ml}$ supernatant was taken for the determination of inorganic phosphorus.

\subsubsection{The Determination of $\mathrm{Ca}^{2+}$ Content}

The determination of $\mathrm{Ca}^{2+}$ content was following the method of Zarcinas with some modification [25]. $0.15 \mathrm{~g}$ dried leaves sample was added with $5 \mathrm{ml} \mathrm{HNO}_{3}$ and treated overnight. After that, $5 \mathrm{ml} \mathrm{HNO}_{3}$ and $1.5 \mathrm{ml} \mathrm{HClO}_{4}$ was added and treated with boiling water bath for $4 \mathrm{~h}$. Then, after using electric furnace and made the leaves nearly dried under $200^{\circ} \mathrm{C}$ treatment, the sample was watered with 0.1 mol L $\mathrm{L}^{-1}$ diluted nitric acid for four times and used distilled water (nearly $10 \mathrm{ml}$ ) add the capacity up to $20 \mathrm{ml}$. The $\mathrm{Ca}^{2+}$ content was measured with atomic absorption spectrophotometer (TAS-990 Super, general).

\section{Results}

\subsection{The Influence on TBARS and $\mathrm{H}_{2} \mathrm{O}_{2}$ of Maize Seedlings After Pretreatment with Glu and Suc Under Salt-Stress}

The relative growth rate can effectively respond the damage degree of abiotic stress [26-28]. As shown in Fig. 1 , the heights of maize under different treatments existed obvious difference. Under non-salt treatment, the aboveground relative growth rate under $\mathrm{G}$ and $\mathrm{T}$ treatment are increased by $8.7 \%$ and $10 \%$ than $\mathrm{CK}$ (Table 1 ), the underground relative growth rate is increased by $4.5 \%$ and $10 \%$ respectively, but the difference was not significant. Comparing with control plants, the aboveground and underground relative growth rate of $\mathrm{S}$ treatment are obviously reduced by $29.7 \%$ and $43.9 \%$ respectively, and the reductions are significantly different. Compared with $\mathrm{S}$ treatments, pretreatment with $0.5 \mathrm{mmol} \cdot \mathrm{L}^{-1}$ Glc and Suc could remarkably increase the relative growth rate of maize, the aboveground and underground relative growth rate of maize under $\mathrm{G}+\mathrm{S}$ treatment are increased by $14.79 \%$ and $44.03 \%$, respectively. Meanwhile, the same indexes under $\mathrm{T}+\mathrm{S}$ treatment are increased by $35.56 \%$ and $72.37 \%$, respectively. However, there are non-significant difference between plants under $\mathrm{M}+\mathrm{S}$ and $\mathrm{S}$ treatments. These results suggest that salt stress has obvious inhibitory effect on plant growth, and pretreatment with Glu and Suc under salt-stress environment could improve salt resistance of plants, the growth of maize seedlings and the accumulation of dry materials. At the same time, the treatment of isotonic mannitol is failed to reach the same effect, which explains that the calming effect is not caused by osmosis. 


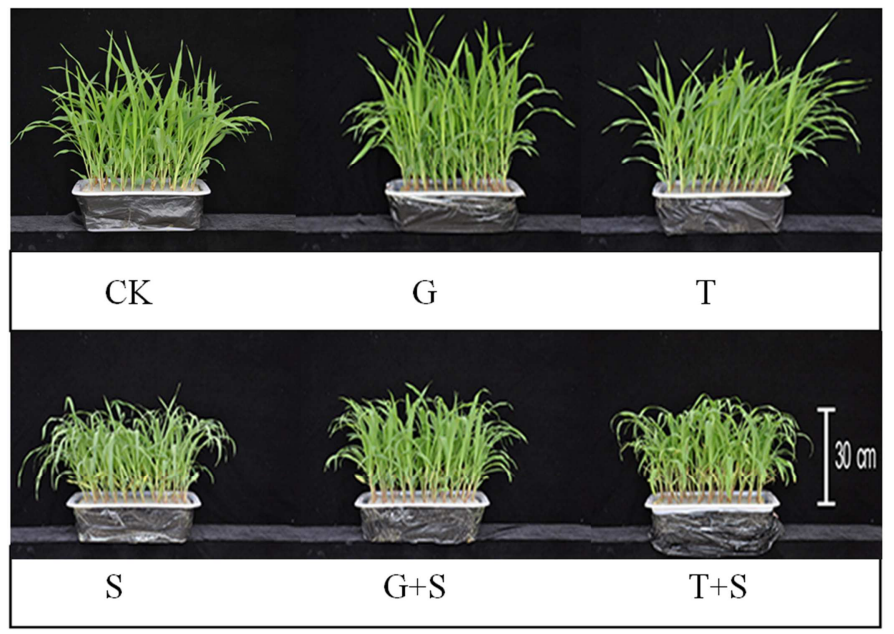

Fig. 1. The increment of salt-tolerance in maize by pretreatment with Glc or Suc.

Note: Maize were pretreated with different treatment and then transferred to salt stress or unsalted stress for 6 days. CK: control; S: salt treatment; G: pretreated with $0.5 \mathrm{mmol} \cdot L^{-1} \mathrm{Glc}$; T: pretreated with $0.5 \mathrm{mmol} \cdot \mathrm{L}^{-1}$ Suc; $G+S$ : salt stressed seedlings pretreated with $0.5 \mathrm{mmol} \cdot L^{-1}$ Glc; $T+S:$ salt stressed seedlings pretreated with $0.5 \mathrm{mmol} \cdot \mathrm{L}^{-1}$ Suc; $M+S$ : salt stressed seedlings pretreated with $0.5 \mathrm{mmol} \cdot \mathrm{L}^{-1}$ mannitol

Table 1. Effects of pretreated with glucose crose on relative growth rate $(R G R)$ in maize seedings under salt stress.

\begin{tabular}{llllllll}
\hline RGR (\%) & CK & G & T & S & G+S & T+S & M+S \\
\hline above-ground & $100.0 \mathrm{ab}$ & $108.7 \mathrm{a}$ & $110.0 \mathrm{a}$ & $70.3 \mathrm{c}$ & $87.0 \mathrm{~b}$ & $95.3 \mathrm{ab}$ & $70.6 \mathrm{c}$ \\
under-ground & $100.0 \mathrm{ab}$ & $104.5 \mathrm{ab}$ & $110.8 \mathrm{a}$ & $56.1 \mathrm{~d}$ & $80.8 \mathrm{c}$ & $96.7 \mathrm{~b}$ & $48.7 \mathrm{~d}$ \\
\hline
\end{tabular}

Treatments described as in Fig. 1. Values with different letters in the same column are significantly different at $\mathrm{P}<0.05$ based on the Duncan test. Values are the average of three replicates, reported as mean $\pm \mathrm{SE}$
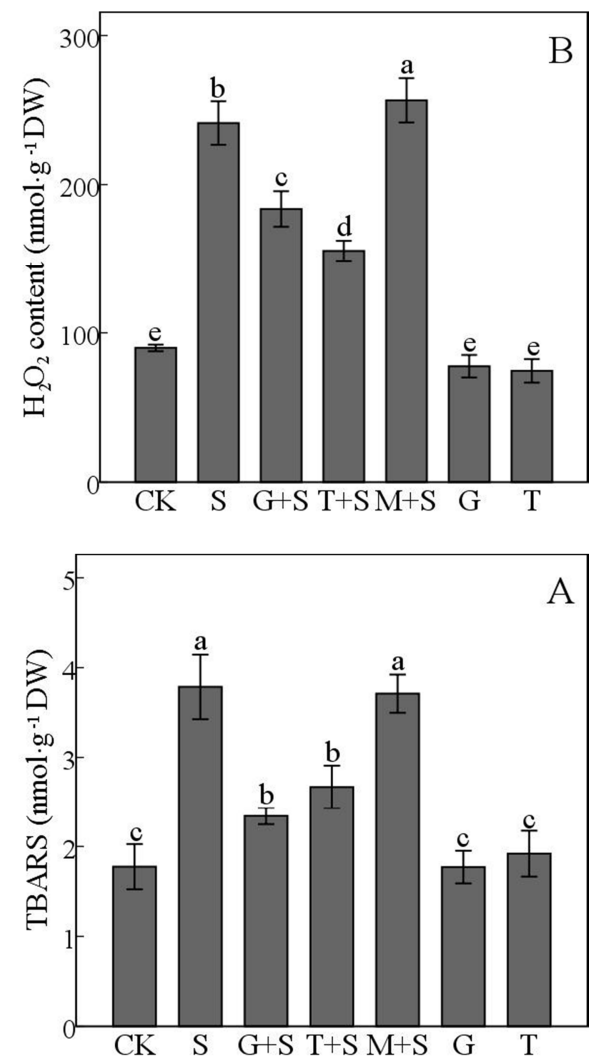

Fig. 2. Effects of salt stress on the TBARS (A) and $\mathrm{H}_{2} \mathrm{O}_{2}(B)$ contents in leaves of maize seedings pretreated with glucose or sucrose
TBARS is the product of glucosinolates barbituric acid. According to figure 2 (A), the content of TBARS in maize leaves significantly increased under salt treatment. Compared with $\mathrm{S}$ treatment, pretreatment with $0.5 \mathrm{mmol} \cdot \mathrm{L}^{-1} \mathrm{Glc}$ and Suc could remarkably reduce the TBARS contents in maize leaves, reduced by $38.26 \%$ and $29.63 \%$, respectively. However, there are no significant difference between $\mathrm{M}+\mathrm{S}$ and $\mathrm{S}$ treatments.

$\mathrm{H}_{2} \mathrm{O}_{2}$ is one of the most important active oxygen in plants [29]. As shown in figure 2 (B), the $\mathrm{H}_{2} \mathrm{O}_{2}$ contents in leaves after salt treatment increased significantly. Among them, the $\mathrm{H}_{2} \mathrm{O}_{2}$ content under $\mathrm{M}+\mathrm{S}$ treatment is the highest one (2.85-fold over the control). Comparing with $\mathrm{S}$ treatment, treatment with $\mathrm{G}+\mathrm{S}$ and $\mathrm{T}+\mathrm{S}$ reduced the $\mathrm{H}_{2} \mathrm{O}_{2}$ contents remarkably, namely $23.87 \%$ and $35.56 \%$, respectively. Which means the $\mathrm{H}_{2} \mathrm{O}_{2}$ contents in leaves under $\mathrm{T}+\mathrm{S}$ treatment is lower than that under $\mathrm{G}+\mathrm{S}$ treatment. These results indicate that pretreatment with Suc and Glc could reduce the accumulation of active oxygen in maize seedling significantly, which could reduce the damage of membrane lipid peroxidation to plant cells and improve the stability of cells.

\subsection{The Influence on ASA and GSH Contents in Maize \\ Seedlings and ASA/DHA, GSH/GSSG Under Salt-Stress After Pretreatment with Glc and Suc}

Both ASA and GSH is ROS scavenger in plants and the main components of enzymatic antioxidant system. As shown in figure 3, with pretreatment of Glc or Suc under non-salt stress, the ASA and GSH contents in maize leaves are 
increased remarkably. Comparing with the control plants, the ASC and GSH contents in plants under G treatment increased by $10.41 \%$ and 4.28 , respectively, while increased by $11.97 \%$ and $4.57 \%$ under $\mathrm{T}$ treatment. However, there is no significant difference between $\mathrm{G}$ and $\mathrm{T}$ treatments. Whereas, under salt-stress environment, the ASA and GSH contents in maize leaves are obviously decreased by $34.34 \%$ and $29.33 \%$, respectively, comparing with control plants. Moreover, under pretreatment with Glc and Suc, the ASA and GSH contents in maize seedlings are increased significantly. Comparing with $\mathrm{S}$ treatment, the ASA and GSH contents in maize seedlings under $\mathrm{G}+\mathrm{S}$ treatment increased by $30.4 \%$ and $17.9 \%$, respectively. Meanwhile, these indexes increased by $33.36 \%$ and $18.15 \%$ under $\mathrm{T}+\mathrm{S}$ treatment. There is no remarkable difference between treatments with $\mathrm{G}+\mathrm{S}$ and $\mathrm{T}+\mathrm{S}$. What is more, the ASA and GSH contents in maize seedlings under $\mathrm{M}+\mathrm{S}$ treatment are obviously lower than that treated with $\mathrm{S}$.

ASA/DHA and GSH/GSSG are two important indexes which could reflect the REDOX situation inside plants, and GSH/GSSG has already be confirmed as a signaling which involved in plant response regulation under biotic and abiotic stresses [30]. According to figure 4, under non-salt stress environment, ASA/DHA and GSH/GSSG in leaves can be greatly increased after pretreatments with Glc and Suc. Compared with control plants, the ASA/DHA and GSH/GSSG contents in plants under salt treatment are greatly reduced, while pretreatments with $0.5 \mathrm{mmol} \cdot \mathrm{L}^{-1} \mathrm{Glc}$ and Suc could increase the ASA/DHA and GSH/GSSG contents in maize leaves under salt stress. Comparing with $S$ treatment, the ASA/DHA and GSH/GSSG contents in maize leaves under $\mathrm{G}+\mathrm{S}$ treatment increased by $38.03 \%$ and $26.27 \%$, respectively. These results suggest that under normal circumstances, with pretreatments of Glc and Suc, both the ASA, GSH contents and ASA/DHA, GSH/GSSG in maize leaves could be significantly increased, which play positive roles in the maintance of intracellular REDOX balance. The pretreatment of Glc and Suc under salt-stress environment could increase the ASA and GSH contents and ASA/DHA and GSH/GSSG greatly, which could effectively ease the damage in ASA-GSH cycle and improve the intracellular REDOX potential. Thus could enhance the antioxidant capacity of plant cells and help the plants balance the active oxygen metabolism in the cell in a better way.

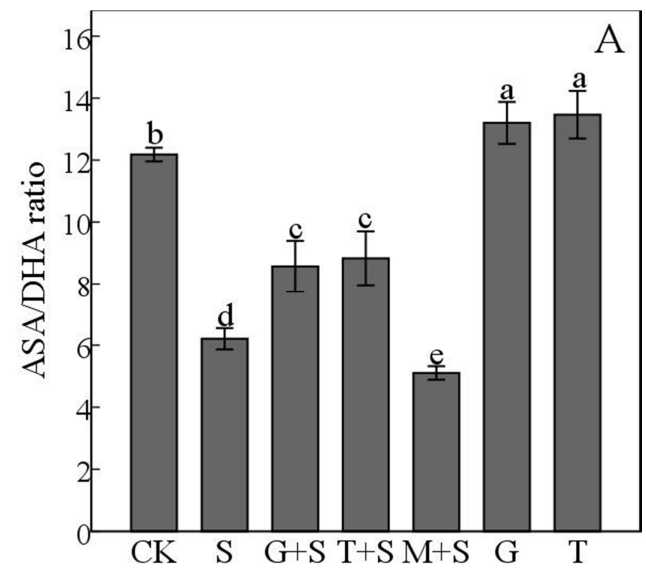

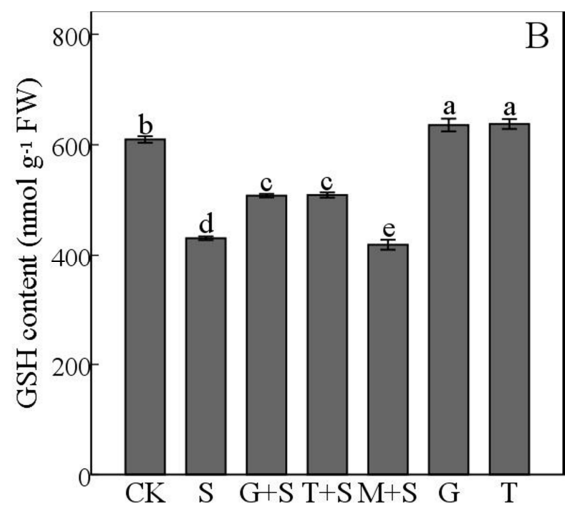

Fig. 3. Effects of pretreated with glucose or sucrose on ASA (A) and GSH (B) contents in leaves of maize seedings under salt stress.
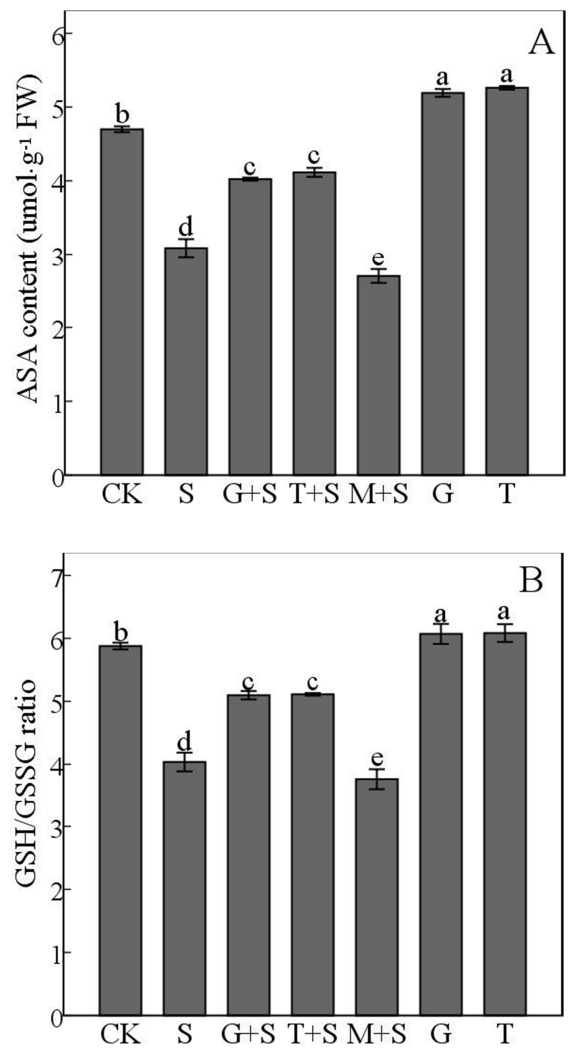

Fig. 4. Effects of pretreated with glucose or sucrose on ASA/DHA (A) and $G S H / G S S G(B)$ in leaves of maize seedings under salt stress.

\subsection{The Influence on the Activeness of G6PDH in Maize Seedlings Under Salt-Stress After Pretreatment with Glc and Suc}

G6PDH is one of the speed-limit enzymes in pentose-phophate pathway (OPP). As shown in figure 5, the pretreatment of Glc and Suc under non-salt stress could increase the activeness of G6PDH in maize leaves remarkably. Compared with control plants, the activeness of G6PDH in maize leaves under $\mathrm{G}$ and $\mathrm{T}$ treatments are increased $15.61 \%$ and $10.71 \%$, respectively. This indicates that under normal environment, pretreatment with Suc and Glc could help maintain the activeness of G6PDH in maize 
leaves. However, comparing with control plants, the activeness of G6PDH in maize leaves under $\mathrm{S}$ treatment reduced by $34.51 \%$, which indicates that salt-stress could remarkably reduce the activeness of G6PDH in maize leaves. While comparing with $\mathrm{S}$ treatment, the activeness of G6PDH in maize leaves under pretreatment with Glc and Suc are increased by $23.35 \%$ and $26.74 \%$, respectively, while there is no significant difference between $\mathrm{G}+\mathrm{S}$ and $\mathrm{T}+\mathrm{S}$ treatments. These data indicate that pretreatment with Suc and Glc under salt-stress could greatly slow down the declining rate of G6PDH, maintain the normal operation of OPP metabolism in cells effectively, positively influence the accumulation of NADPH in maize leaves, and plays an important role in the maintenance of intracellular REDOX balance.

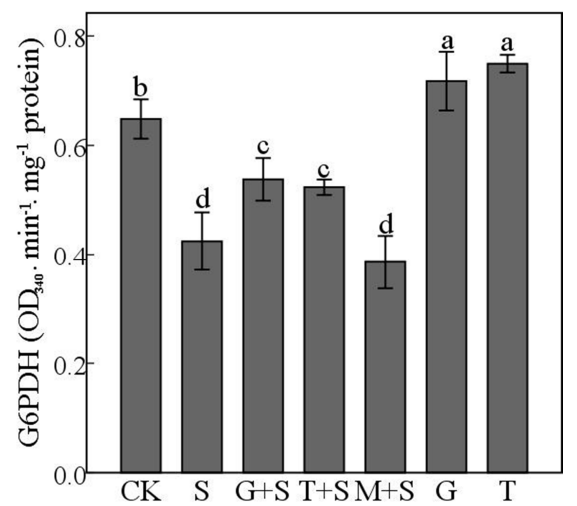

Fig. 5. Effects of pretreated with glucose or sucrose on the G6PDH activity in leaves of maize seedings under salt stress.

\subsection{The Correlate Analysis of G6PDH Activity and Various Physiological Indicators in Maize Seedlings After Salt-Stress}

According to Table 2, G6PDH activity has a very significant positive correlation with the contents of ASA and GSH and a remarkable negative correlation with the contents of $\mathrm{H}_{2} \mathrm{O}_{2}$ and TBARS. This indicates that the G6PDH activity is closely related with the stronger antioxidant capacity after treatment with Suc and Glc.

Table 2. Correlation between G6PDH activity and several physiological indexes of maize under salt stress.

\begin{tabular}{lllll}
\hline & ASA & GSH & $\mathbf{H}_{2} \mathbf{O}_{2}$ & TBARS \\
\hline G6PDH & $0.988^{* *}$ & $0.991^{* *}$ & $-0.977^{* *}$ & $-0.929^{* *}$ \\
ASA & & $0.983^{* *}$ & $-0.955^{* *}$ & $-0.937^{* *}$ \\
GSH & & & $-0.980^{* *}$ & $-0.959^{* *}$ \\
$\mathrm{H}_{2} \mathrm{O}_{2}$ & & & & $0.927^{* *}$ \\
TBARS & & & & \\
\hline
\end{tabular}

\subsection{The Influence on $\mathrm{Ca}^{2+}$-ATPase Activity and $\mathrm{Ca}^{2+}$ Content in Maize Seedlings Under Salt-Stress After Pretreatments with Glc and Suc}

$\mathrm{Ca}^{2+}$-ATPase plays a significant role in maintaining the inside- and outside-cell $\mathrm{Ca}^{2+}$ concentration [31]. As shown in figure 6 (A), comparing with control plants, the activity of $\mathrm{Ca}^{2+}$-ATPase in maize leaves under non-salt stress after pretreatment with Suc increased by $6.92 \%$. This illustrate that the pretreatment with Suc under non-salt stress environment could induce the increase of activity of $\mathrm{Ca}^{2+}$-ATPase in maize leaves. Comparing with control plants, salt stress could reduce the activity of $\mathrm{Ca}^{2+}$-ATPase in maize leaves significantly, and shows a $38.4 \%$ decrease in data. Comparing with $\mathrm{S}$ treatment, the activity of $\mathrm{Ca}^{2+}$-ATPase in maize leaves after pretreatment with Suc under salt-stress condition increased by $18.63 \%$, while there is no significant change after pretreatment with Glc. These indicate that under salt-stress environment, pretreatment with Suc could improve the activity of $\mathrm{Ca}^{2+}$-ATPase in maize leaves and help to maintain the intracellular $\mathrm{Ca}^{2+}$ concentration.

$\mathrm{Ca}^{2+}$ is not only an essential element in plants, but also involved in plants responses to a variety of adversities as second messenger. However, when the $\mathrm{Ca}^{2+}$ contents in plants is too high, it may cause the disorders of plant metabolic and even lead to cell death [32]. As shown in figure 6 (B), the $\mathrm{Ca}^{2+}$ contents in maize leaves were remarkably improved after pretreatment with Suc under non-salt stress. Under the treatment with salt, the $\mathrm{Ca}^{2+}$ contents of maize leaves under different treatment were all display raise in some extent, although the rising extent under $\mathrm{T}+\mathrm{S}$ treatment is the least and has a significant difference compared with $\mathrm{S}$ treatment. These data suggested that the $\mathrm{Ca}^{2+}$ content could be stabilized with pretreatment with Suc under salt-stress, which could guarantee the normal physiological metabolism and signal transduction in plants.
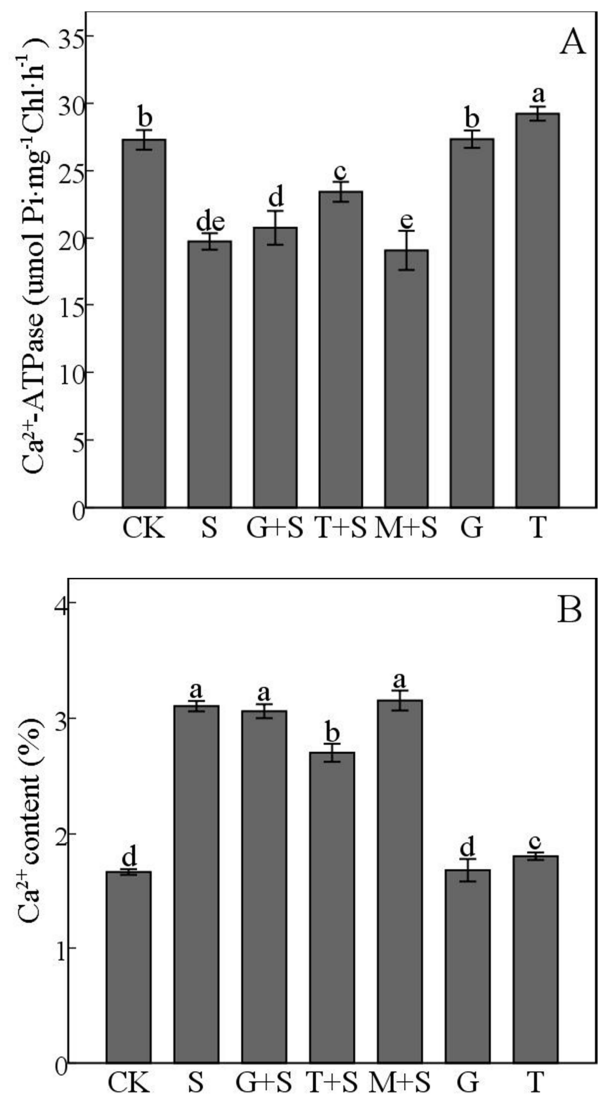

Fig. 6. Effects of pretreated with glucose or sucrose on the $\mathrm{Ca}^{2+}$-ATPase activity (A) and $\mathrm{Ca}^{2+}$ content (B) in leaves of maize seedings under salt stress. 


\section{Conclusion}

Biotic and abiotic stresses (high salt contents, drought, germ infection, etc.) in different kinds might lead to the deficiency of energy in plants and has a negative influence on plants growth, which may turn into death eventually, so the maintenance of energy balance inside the plants is vital for plants resistance to adversity [33]. In this study, it is found that pretreatment with Glc and Suc could promote the growth of seedlings and accumulation of dried substance in maize, reduce the water loss in cell caused by salt stress and improve the growth of maize seedlings under salt-stress condition. The data in this research is also in line with the former studies which pointed out that exogenous Glc and Suc could obviously alleviate the damage caused by salt, herbicides, and phosphorus starvation stress in both wheat and Arabidopsis thaliana [34-36]. In conclusion, the results in this study showed that exogenous sugar can help plants responses to adversity stresses in a better way.

Under salt-stress environment, plants will accumulate excessive ROS and lead to the increase of TBARS production that could cause damage to plants cells [37]. In this study, pretreatment with Glc and Suc could reduce the content of TBARS and $\mathrm{H}_{2} \mathrm{O}_{2}$ in maize leaves which means the pretreatment with Glc and Suc could reduce the damage caused by active oxygen radicals and increase the stability of cell membrane under salt-stress condition. Both ASA and GSH are antioxidants widely exist in plants and take part in a large amount of redox reaction. These two antioxidants can not only react with ROS directly, but also play roles in ASA-GSH cycle which could clear $\mathrm{H}_{2} \mathrm{O}_{2}$ in plants bodies. Thus, the contents of ASA/DHA and GSH/GSSG can reflect the condition of redox reaction in plants. Abiotic stress might lead to the imbalance of oxidative system inside plants and cause oxidative stress and peroxidation of cell lipid, thus the maintenance of the redox balance in plants is vital for plants resistance to adversity [38]. Research conducted by Smimoff and Pallanca (1996) [39] showed that exogenous Glc and Suc could improve the ASA content in Arabidopsis thaliana under darkness. In this study, it is found that pretreatment with Glc and Suc could increase the content of ASA and GSH in maize leaves and regulate ASA/DHA and GSH/GSSG, which could ease the damage caused by ASA-GSH cycle effectively and increase the intracellular redox potential. As a result, the cellular antioxidant capacity is enhanced. The study conducted in broccoli showed that exogenous Suc could induce the expression of Suc synthetase gene and increase the ASA content in leaves in vitro [40]. These data indicates that exogenous sugars can maintain the balance of active oxygen metabolism effectively, which is one of the important mechanism in plant alleviate adversity stresses.

G6PDH is one the key enzymes of OPP pathway and controls the nonreversibiliy of the first step in OPP pathway; the activity of G6PDH plays an important role in regulation of redox balance and removement of ROS [41]. It is found that exogenous glucose can enhance the activity of G6PDH in potato sytoplasm. In both the mammalian and plant cells, the increase of G6PDH expression could enhance the antioxidant capacity $[42,43]$. In this study, the activity of G6PDH could be remarkably reduced under salt-stress, while the pretreatment with $0.5 \mathrm{mmol} \cdot \mathrm{L}^{-1}$ Glc and Suc could increase the activity of G6PDH of maize leaves under salt-stress. These showed that pretreatment with Glc and Suc could slow down the declining rate of G6PDH under salt-stress condition, maintain the normal operation of OPP metabolism effectively, and promote the accumulation of NADPH of maize leaves. All of these mentioned above plays an important role the maintenance of intracellular redox balance. In addition, pretreatment with Suc and Glc could improve the G6PDH activity in maize leaves effectively under normal growing conditions, this might caused by the increasing soluble sugar contend caused by Suc and Glc (data not shown). Through analysis the correlation between G6PDH activity and several relevant physiological indexes, it is safe to say that the G6PDH activity is positively related with both the content of ASA/GSH. Meanwhile, it is negatively related with the content of $\mathrm{H}_{2} \mathrm{O}_{2}$ and TBARS. All this data indicates that G6PDH is closely related to the relatively high antioxidant capacity under salt-stress, and it may acts as a molecular signal in the induction of maize salt resistance. Among these, G6PDH is mostly related with ASA and GSH, which is 0.988 and 0.991 respectively. These showed that the exogenous Glc and Suc could increase the ASA and GSH content is largely dependent on OPP pathway.

As one of the most important second messengers in plant cells, $\mathrm{Ca}^{2+}$ can participate many adversity signal transduction. Plant membrane $\mathrm{Ca}^{2+}$-ATPase is one of the main channel for intercellular $\mathrm{Ca}^{2+}$ transportation, it plays an important role in both the maintenance of $\mathrm{Ca}^{2+}$ balance inside- and outside cell and the improvement of plant resistance [44]. In this study, the $\mathrm{Ca}^{2+}$-ATPase activity in maize leaves is reduced under salt-stress, which leads to a higher concentration of $\mathrm{Ca}^{2+}$ insider plant cells, and pretreatment with Suc could remarkably induce the activity increase of $\mathrm{Ca}^{2+}$-ATPase in maize leaves. Interestingly, under normal and salt-stress conditions, pretreatment with Suc could increase or reduce the intracellular $\mathrm{Ca}^{2+}$ concentration respectively. These may lead to the conclusion that pretreatment with Suc could activate the calcium signals in maize and increase the $\mathrm{Ca}^{2+}$ content, and $\mathrm{Ca}^{2+}$ could start the cascade reaction under salt-stress in order to regulate the adaptability of maize. It is worth to mention that pretreatment with Glc cause non difference in both the $\mathrm{Ca}^{2+}$-ATPase activity and $\mathrm{Ca}^{2+}$ content, which means that Suc and Glc could improve salt resistance of maize in different ways. In addition, comparing with pretreatment with Glc, pretreatment with Suc showed better ability in the clearness of $\mathrm{H}_{2} \mathrm{O}_{2}$ which is produced under salt-stress, higher activity of $\mathrm{Ca}^{2+}$-ATPase and higher $\mathrm{Ca}^{2+}$ content. Thus, it is remains further study that Suc might take part in the process of $\mathrm{H}_{2} \mathrm{O}_{2}$ clearness through induce the $\mathrm{Ca}^{2+}$ signal in plants. 


\section{References}

[1] Zhang J F, Zhang D, Zhou J X, Liu G F, Li D X. World resources of saline soil and main amelioration measures. $J$ Soil Water Conserv 2005, 12: 32-34.

[2] Wang W, Vinocur B, Altman A. Plant responses to drought, salinity and extreme temperatures: towards genetic engineering for stress tolerance. Planta, 2003, 218: 1-14.

[3] Waseem S, Syed S A, Inayatullah T. Sugar signaling in plant growth and development. Plant signaling: Understanding $m$ the olecular crosstalk, 2014, 29: 93-116.

[4] Hanson J, Smeekens S. Sugar perception and signaling an update. Curr Opin Plant Biol, 2009, 12: 562-567.

[5] Gibson S I. Control of plant development and gene expression by sugar signalling. Current Opinion in Plant Biology, 2005, 8: 93-102.

[6] Eveland A L, Jackson D P. Sugars, signalling, and plant development. J Exp Bot, 2012, 63: 3367-3377.

[7] Bolouri-Moghaddam M R, Roy K L, Xiang L, Rolland F, Ende W V. Sugar signalling and antioxidant network connections in plant cells. FEBS J, 2010, 277: 2022-2037.

[8] Coue'e I, Sulmon C, Gouesbet G, Amrani A E. Involvement of soluble sugars in reactive oxygen species balance and responses to oxidative stress in plants. $J$ Exp Bot, 2006, 57(3): 449-459.

[9] Xiang L, Li Y, Rolland F, Ende W V. Neutral invertase, hexokinase and mitochondrial ROS homeostasis. Plant Signal Behav, 2011, 6: 1567-1573.

[10] Hu M Y, Shi Z G, Zhang Z B, Zhang Y J, Li H. Effects of exogenous glucose on seed germination and antioxidant capacity in wheat seedlings under salt stress. Plant Growth Regul, 2012, 68: 177-188.

[11] Hauschild R, Von S A. Differential regulation of glucose-6-phosphate dehydrogenase is enzyme activities in potato. Plant Physiol, 2003, 133: 47-62.

[12] Siringam K, Juntawong N, Chaum S, Boriboonkaset $T$, Kirdmanee C. Salt tolerance enhancement in indica rice (Oryza sativa L.) seedlings using exogenous sucrose supplementation. Plant Omics J, 2012, 5(1): 52-59.

[13] Boriboonkaset T, Bunyajinda V, Chaum S, Kirdmanee C. Effect of exogenous sugar classes and concentrations on salt-tolerant ability of indica rice (Oryza sativa L.). Acta Horticul, 2007, 746: 155-163.

[14] Price J, Laxmi A, Martin S K, Jang J C. Global transcription profiling reveals multiple sugar signal transduction mechanisms in Arabidopsis. Cell, 2004, 16: 2128-2150.

[15] Seki M, Narusaki M, Ishida J, Nanjo T, Fujita M, Oone Y, Kamiya A, Nakajima M, Enju A, Sakurai T, Satou M, Akiyama K, Taji T, Shinozaki K Y, Carninci P, Kawai J, Hayashizaki K Y and Shinozaki K. monitoring the expression profiles of 7000 Arabidopsis genes under drought, cold and high salinity stresses using a full length cDNA microarray. $J$ Plant, 2002, 31: 279-292.

[16] Kingsbury R W, Epstein E, Peary R W. Physiological response to salinity inselectea lines of wheat. Plant Physiol, 1984, 74: 417-423.
[17] Hodges D M, Delong J M, Forney C F, Prange R K. Improving the thiobarbituric acid-reactive-substance assay for estimating lipid peroxidation in plant tissues containing anthocyanin and other interfering compounds. Planta, 1999, 207: 604-611.

[18] Velikova V I, Edreva Y A, Oxidative stress and some antioxidant systems in acid rain-treated bean plants-protective role of exogenous polyamines, Plant Sci, 2000, 151: 59-66

[19] Fryer M J, Andrews J R, Oxborough K, Blowers D A, Baker $\mathrm{N}$ R. Relationship between $\mathrm{CO}_{2}$ assimilation, photosynthetic electron transport, and active $\mathrm{O}_{2}$ metabolism in leaves of maize in the field during periods of low temperature. Plant Physiol, 1998, 116: 571-580.

[20] Nagalakshmi N, Prasad M N V. Responses of glutathione cycle enzymes and glutathione metabolism to copper stress in Scenedesmus bijugatus. Plant Sci, 2001, 160: 291-299.

[21] Brouquisse R, James F, Raymond P, Pradet A. Study of glucose starvation in excised maize root tips [J]. Plant Physiol, 1991, 96: 619-626.

[22] Bradford M M. A rapid and sensitive method for the quantitation of microgram quantities of protein utilizing the principle of protein-dye binding [J]. Analytical Bioche, 1976, 72: $248-254$.

[23] Liu P, Li M J. Experiment technology of plant physiology. Beijing: Science Press, 2007: 106-108. (in Chinese)

[24] Huang Z H. Experimental Manual on Plant Physiology. Shanghai: Shanghai Scientific and Technical Publishers, 1985: 111-115 (in Chinese).

[25] Zarcinas B A, Carwright B, Spouncer L R. Nitric acid digestion and multi-element analysis of plant material by inductively coupled plasma spectrometry. Commun Soil Sci Plan, 1987, 18: 131-146.

[26] Chi C M, Wang Z C, Li B. Effects of complex salinity-alkalinity stress on germination and seedling growth of sorghum broom (sorghum bicolor (L.) Moench). Agric Res Arid Areas, 2008, 26(4): 148-151 (in Chinese with English abstract).

[27] Gao C H, Hu J, Zheng Y Y, Zhang S. Antioxidant enzyme activities and proline content in maize seedling and their relationships to cold endurance. Chin J App Ecol, 2006, 17(6): 1045-1050 (in Chinese with English abstract).

[28] Effects of alkali stress on Aneurolepidium chinense and Helianthus annuus. Chin J Appl Ecol, 2005, 16(8): 1497-1501 (in Chinese with English abstract).

[29] Petrov V D, Van B F. Hydrogen peroxide-a central hub for information flows in plant cells. AoB Plants, 2012, 10.1093/aobpla/pls014.

[30] Tausz M, Sircelj H, Grill D. The glutathione system as a stress marker in plant ecophysiology is a stress-response concept valid. Exp Bot, 2004, 55: 1955-1962.

[31] Zhang Z S, Li R Q, Wang J B. Effects of heat stress on $\mathrm{Ca}^{2+}$ ATP activity in the mesophyll cells of pepper pretreated with $\mathrm{Ca}^{2+}$. Acta Phytophysiol Sin, 2001, 27(6): 451-454.

[32] Zheng Z Z, Shen J Q, Pan W K. Calcium sensors and their stress signaling pathways in plants. Hereditas, 2013, 35(7): 875-884. 
[33] Iwona M, Lech R. The role of sugar signaling in plant defense responses against fungal pathogens. Acta Physiol Plant 2014, 36: $1607-1619$.

[34] Hu M Y, Shi Z G, Zhang Z B, Zhang Y J, Li H. Effects of exogenous glucose on seed germination and antioxidant capacity in wheat seedlings under salt stress. Plant Growth Regulation, 2012, 68: 177-188.

[35] Sulmon C, Gouesbet G, Amrani A E, Coue'e I. Involvement of the ethylene-signalling pathway in sugar-induced tolerance to the herbicide atrazine in Arabidopsis thaliana seedlings. Journal of Plant Physiology, 2007, 57(3): 449-459.

[36] Karthikeyan A S, Varadarajan D K, Jain A, Held M A, Carpita N C, Raghothama K G. Phosphate starvation responses are mediated by sugar signaling in Arabidopsis. Planta, 2007, 225: 907-918.

[37] Sohrabi Y, Heidari G, Weisany W, Golezani K G, Mohammadi $\mathrm{K}$. Changes of antioxidative enzymes, lipid peroxidation and chlorophyll content in chickpea types colonized by different Glomus species under drought stress. Symbiosis, 2012, 56(1): 5-18.

[38] Miller G, Suzuki N, Ciftci-Yilmaz S, Miller R. Reactive oxygen species homeostasis and signaling during drought and salinity stresses. Plant Cell Environ, 2010, 33: 453-467.
[39] Smirnoff N, Pallanca J E. Ascorbate metabolism in relation to oxidative stress. Biochem Soc Trans, 1996, 24: 472-478.

[40] Nishikawa N, Kato M, Hyodo H, Ikoma Y, Sugiura M, Yano M. Effect of sucrose on ascorbate level and expression of genes involved in the ascorbate biosynthesis and recycling pathway in harvested broccoli florets. J Exp Bot, 2005, 56: $65-72$.

[41] Abul K A, Fei W, Hak R K. Identification of a Novel Sugar Compound from Korean Pine Seeds. Food Sci. Biotechnol, 2015, 24(6): 2011-2015.

[42] Salvemini F, Franze'A, Iervolino A, Filosa S, Salzano S, Ursini MV. Enhanced glutathione levels and oxidoresistance mediated by increased glucose-6-phosphate dehydrogenase expression. J Biol Chem, 1999, 274: 2750-2757.

[43] Dong H S, Tae L K, Man H C, Sang W L, Seong H B. Characterization of Arabidopsis mutants insensitive to high sugar concentrations. J Korean Soc Appl Biol Chem, 2015, 58(5): 741-744.

[44] Zheng ZZ, Shen JQ, Pan WH, Pan JW. Calcium sensors and their stress signaling pathways in Plant. Journal of genetic, 2013, 35(7): 875-884. 